\title{
O DESENVOLVIMENTO COMO NÚCLEO DE IRRADIAÇÃO ENTRE O DIREITO PRIVADO E O DIREITO PÚBLICO
}

\author{
EL DESARROLLO COMO NÚCLEO DE EXPANSIÓN \\ ENTRE EL DERECHO PRIVADO Y EL DERECHO \\ PÚBLICO
}

Érica Guerra da Silva*

Resumo: Este estudo tem por objetivo demonstrar mais um caminho da incidência dos direitos humanos fundamentais nas relações privadas, considerando o direito ao desenvolvimento. Para alcançar esse propósito, buscou-se fundamento teórico nos textos normativos da Organização das Nações Unidas (ONU), Constituição da República Federativa do Brasil, de 1988, e legislações comerciais dos Estados Partes do Mercado Comum do SulMERCOSUL. Os principais resultados indicam que as legislações comerciais de alguns Estados Partes do MERCOSUL evoluíram para dispor sobre o melhor momento de liquidação do ativo para evitar ou minimizar os prejuizos dos credores no direito falimentar. Ao final, apresentam-se sugestões tendo em vista as legislações comerciais dos Estados Partes do MERCOSUL, para formulação de normas fundamentais sobre o direito concursal.

Resumen: Este estudio tiene por objetivo demostrar una nueva forma de incidencia de los derechos humanos fundamentales en las relaciones privadas, considerando el derecho al desarrollo. Para alcanzar ese propósito, se buscó fundamento teórico en los textos normativos de la Organización de las Naciones Unidas (ONU), Constitución de la República Federativa de Brasil de 1988, y legislaciones comerciales de los Estados Partes del Mercado Común del Sur (MERCOSUR). Los principales resultados indican que las legislaciones comerciales de algunos Estados Partes del MERCOSUR evolucionaron para disponer sobre el mejor momento de liquidación del activo para evitar o minimizar los perjuicios de los acreedores en el derecho concursal. Al final, se presentan sugerencias con miras a las legislaciones comerciales de los Estados Partes del MERCOSUR, para la formulación de normas fundamentales sobre el derecho concursal.

* Doutoranda em Direito pela Universidade Estácio de Sá. Membro Efetivo do Instituto dos Advogados Brasileiros. Membro Permanente da Comissão de Direito Empresarial. Membro do Instituto Brasileiro de Direito Empresarial. Professora Assistente da Universidade Federal Rural do Rio de Janeiro (UFRRJ). Autora de Livros e artigos jurídicos. 
Palavras-chave: Direito ao desenvolvimento, Direito da integração, Norma fundamental do direito falimentar

Palabras clave: Derecho al desarrollo, Derecho de la integración, Norma fundamental del derecho concursal

\section{INTRODUÇÃO}

O objetivo do presente trabalho é mostrar que o direito ao desenvolvimento representa mais um caminho da incidência dos direitos humanos fundamentais nas relações privadas, através da análise do melhor momento de liquidação do ativo para evitar ou minimizar os prejuízos dos credores no direito falimentar.

Serão examinadas as mudanças ocorridas no século passado, quando se iniciou à integração dos países da América Latina e a constituição do Mercado Comum do Sul-MERCOSUL, visando extrair mais elementos propulsores do desenvolvimento econômico e a elevação do padrão de vidas das pessoas.

Asempresassãoimportantesagentes depromoçãododesenvolvimento econômico de um país, assim como de seu avanço tecnológico. Uma vez no exercício de atividade economicamente organizada, a atividade empresarial adquire relevância nos ordenamentos jurídicos, eis que deve cooperar para efetividade do bem-estar social.

Para tanto, este trabalho apresenta-se da seguinte forma: no item 2 estuda-se a evolução do conceito de desenvolvimento e a classificação do direito ao desenvolvimento como direito humano fundamental pela Organização das Nações Unidas. No item 3 examina-se a integração dos países como direção à concepção progressista da América Latina, sob o enfoque do direito ao desenvolvimento. No item 4 analisam-se as legislações comerciais de direito falimentar dos mercados integrados do MERCOSUL no contexto histórico. No item 5 estudam-se as regras específicas do início do procedimento de liquidação dos bens no processo de falência nas legislações dos Estados Partes do MERCOSUL.

\section{O DIREITO AO DESENVOLVIMENTO COMO DIREITO HUMANO FUNDAMENTAL}

O direito privado, direito civil ${ }^{1}$ e direito comercial, tem passado por

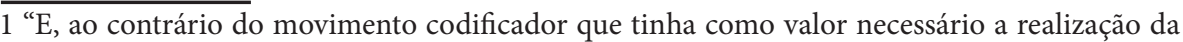
pessoa em seus aspectos patrimoniais, o constitucionalismo social, abraçado pela Constituição Cidadã de 1988, acentua a raiz antropocêntrica do ordenamento jurídico. O patrimônio assume papel de coadjuvante, num fenômeno que se denominou de repersonalização." FACHIN Melina Girardi, PAULINI Umberto (2008) "Problematizando a eficácia dos direitos fundamentais nas relações entre particulares: ainda e sempre sobre a constitucionalização do Direito Civil”. Diálogos sobre direito civil - volume 2. Rio de Janeiro: Renovar. 2008, p. 214.
} 
modificações nos seus lineamentos nos últimos séculos. A ideia de um direito individualista vem sendo afastada pela ideia de valorização dos interesses sociais. Esta mudança passou a ocorrer nas primeiras décadas do século passado ${ }^{2}$ quando, influenciado pelos movimentos sociais e a industrialização, o Estado teve de intervir na economia iniciando-se o Estado de índole social.

No século XX, identificam-se nas Constituições brasileiras princípios e normas que estabelecem deveres sociais no desenvolvimento da atividade econômica privada. O Código Civil brasileiro, de 1916, que esboçava ideias individualistas e patrimonialistas, vê-se enfraquecido pela edição de leis extravagantes que já esquematizavam princípios voltados para justiça social ${ }^{3}$. Konrad Hesse aduzia que o direito constitucional e o direito civil se apoiam e se condicionam ${ }^{4}$.

Com estas mudanças a pessoa humana passa a irradiar as normas de direitos humanos e direitos fundamentais ${ }^{5}$.

$\mathrm{Na}$ segunda metade do século passado, o movimento Direito e Economia ${ }^{6}$ tem defendido a necessidade da atuação conjunta das ciências

2 Para o historiador Eric Hobsbawm: "a Primeira Guerra Mundial assinala "o colapso da civilização (ocidental) do século XIX” e marca o fim do liberalismo econômico que caracterizou aquele século. A partir daí, o mundo passa a ser palco de profundas transformações políticas, sociais e econômicas, produzidas, muitas vezes, no ambiente devastador de grandes conflitos bélicos ou de profundas crises econômicas, mascas da História do Século XX. A queda da Bolsa de Nova York em 1929 e a Grande Depressão dos anos 30 foram determinantes para a adoção pelos governos das principais economias capitalistas e de economias periféricas, de políticas e programas intervencionistas voltados para a sua proteção e expansão"; FERREIRA Mauro Santos (2013) “Desenvolver é preciso". Mercado Comum. Revista Nacional de Economia e Negócios, 21(240), p. 20.

3 "O respeito aos valores e aos princípios fundamentais da República representa a passagem essencial para estabelecer uma correta e rigorosa relação entre o poder do estado e poder dos grupos, entre maioria e minoria, entre poder econômico e os direitos dos marginalizados, dos mais desfavorecidos"; PERLINGIERI Pietro (1999) Perfis do Direito Civil: introdução ao direito civil constitucional. Trad. de Maria Cristina de Cicco. Rio de Janeiro: Renovar, p. 06.

4 "Si la valoración precedente de la naturaliza y de las tareas del actual Derecho Constitucional y del actual Derecho Privado es correcta, ambos aparecen como partes necessárias de um orden jurídico unitario que reciprocamente, se apoyan y se condicionan"; HESSE Konrad (1998) Derecho Constitucional y Derecho Privado. Madrid: Civitas, p. 81.

5 "A pessoa se apresenta como um núcleo de irradiação de direitos. Uma vez que este fenômeno tenha sido captado nos tratados internacionais e nas Constituições, produz-se um enlace, um ponto de contato, entre o Direito Privado e o Direito Público Constitucional. Este fenômeno determina, por sua vez, o exame dos pontos de compatibilidade entre direitos humanos, que constam nas declarações dos tratados internacionais, os direitos fundamentais que declaram as Constituições e os direitos personalíssimos com origem no Direito Privado"; LORENZETTI Ricardo Luis (1998) Fundamentos do Direito Privado. São Paulo: Revistas dos Tribunais, p. 159. 6 "No final da década de 1990, havia organizações profissionais de direito e economia na Âsia, na Europa, no Canadá, nos Estados Unidos, na América Latina e na Austrália. Este campo recebeu o mais alto nível de reconhecimento em 1991 e 1992, quando Prêmios Nobel de Economia sucessivos foram dados a economistas que ajudaram a fundar a análise econômica do direito - Ronald Coase e Gary Becker. (...) A economia proporcionou uma teoria científica para prever os efeitos das sanções legais sobre o comportamento. Para os economistas, as sanções se assemelham aos preços, e, presumivelmente, as pessoas reagem às sanções, em grande parte, da mesma maneira que reagem aos preços. As pessoas reagem aos preços mais altos consumindo menos do produto mais caro; assim, supostamente, elas reagem às sanções legais mais duras praticando menos a atividade sancionada. (...) As leis não são apenas argumentos arcanos, técnicos; elas são instrumentos para atingir objetivos sociais importantes. Para conhecer os 
econômica e jurídica, posto que a economia fornecesse uma base científica útil para avaliar o direito e as políticas públicas e, ainda, prever como as pessoas reagem às leis.

Para as atividades econômicas os termos "crescimento" e "desenvolvimento" deixaram de ser tratados como sinônimos, sendo o primeiro termo entendido como puramente econômico; já o termo desenvolvimento ganhou uma conotação que pressupõe uma ação integrada econômica e social.

No âmbito do direito econômico estabeleceu-se a distinção entre "direito ao desenvolvimento" e "direito do desenvolvimento." O primeiro descreve um direito humano fundamental à luz do conceito de justiça econômica distributiva tratada na Carta das Nações Unidas ${ }^{7}$; já o direito do desenvolvimento relaciona-se com o direito internacional, por buscar soluções para diferenças econômicas entre os diversos Estados.

$\mathrm{O}$ direito ao desenvolvimento passou a ser abordado em tratados internacionais e através de Resoluções das Organizações das Nações Unidas: Resolução 2 (XXXI), de 1975, da Comissão de Direitos Humanos das Nações Unidas; Resolução 4 (XXXIII), de 1977, da Comissão de Direitos Humanos das Nações Unidas; Resolução 41/128, de 1986, da Assembleia Geral que proclamou o direito ao desenvolvimento um dos direitos humanos de terceira geração; em 1993, no art. 10, a Declaração e Programa de Ação de Viena das Nações Unidas (A/CONF 157/123), reconheceu-se o direito ao desenvolvimento como inalienável e parte integrante dos direitos humanos fundamentais ${ }^{8}$.

No Acordo Constitutivo da Organização Mundial do Comércio,

efeitos das leis sobre esses objetivos, os juízes e outros legisladores precisam ter um método para avaliar os efeitos das leis sobre valores sociais importantes. A economia prevê os efeitos das políticas públicas sobre a eficiência”; COOTER Robert, ULLEN Thomas (2010) Direito \& Economia. Trad. Luís Marcos Sander, Francisco Araújo a Costa. 5ed. Porto Alegre: Bookman, p. 24-26.

7 Declaração Universal dos Direitos Humanos (1948) - Artigo XXII: “Toda pessoa, como membro da sociedade, tem direito à segurança social e à realização, pelo esforço nacional, pela cooperação internacional de acordo com a organização e recursos de cada Estado, dos direitos econômicos, sociais e culturais indispensáveis à sua dignidade e ao livre desenvolvimento da sua personalidade".

8 “10. A Conferência Mundial sobre Direitos Humanos reafirma o direito ao desenvolvimento, conforme estabelecido na Declaração sobre o Direito ao Desenvolvimento, como um direito universal e inalienável e parte dos direitos humanos fundamentais. Como afirma a Declaração sobre o Direito ao Desenvolvimento, a pessoa humana é o sujeito central do desenvolvimento. Embora o desenvolvimento facilite a realização de todos os direitos humanos, a falta de desenvolvimento não poderá ser invocada como justificativa para se limitarem direitos humanos internacionalmente reconhecidos. Os Estados devem cooperar uns com os outros para garantir o desenvolvimento e eliminar os obstáculos ao mesmo. A comunidade internacional deve promover uma cooperação internacional eficaz visando à realização do direito ao desenvolvimento. O progresso duradouro necessário à realização do direito ao desenvolvimento exige políticas eficazes de desenvolvimento em nível nacional, bem como relações econômicas equitativas e um ambiente econômico favorável em nível internacional"; RISTER Carla Abrantkoski (2007) Direito ao Desenvolvimento: Antecedentes, Significados e Consequências. Rio de Janeiro: Renovar, p. 63. 
de 1995, as partes reconhecem "que as suas relações na esfera da atividade comercial e econômica devem objetivar a elevação dos níveis de vida, o pleno emprego (...)"

A Constituição da República Federativa do Brasil de 1988, no seu art. 3², define como objetivo fundamental: II - garantir o desenvolvimento nacional.

A Lei 11.101/2005, lei de Recuperação de Empresa e Falência no ordenamento jurídico brasileiro, reconhece a importância da manutenção da empresa para vida social. Ciente que a reorganização econômica da empresa auxilia na observância de sua função social.

\section{O DIREITO AO DESENVOLVIMENTO E AS LEGISLAÇÕES INTERNAS NOS MERCADOS INTEGRADOS DO MERCOSUL}

O direito humano fundamental ao desenvolvimento, como reconhecido no âmbito das Nações Unidas, resultou em reestruturações nas relações entre países que pertencem a uma mesma região e possuíam características comuns.

Em meados do século passado, vários países da América Latina vivenciavam a expansão industrial e o processo de substituição das importações.

A integração dos países da América Latina visou corrigir as distorções no progresso tecnológico, nos mecanismos de expansão do comércio exterior e promoção das empresas regionais ${ }^{10}$, para extrair mais elementos propulsores do desenvolvimento econômico e a elevação do padrão de vidas das pessoas.

A ONU, em 1948, criou a CEPAL - Comissão Econômica para América Latina, com objetivo de tratar das questões que caracterizavam as economias periféricas, a estrutura pouco favorável ao progresso técnico e à acumulação de capital ${ }^{11}$.

A constituição do MERCOSUL iniciou-se com o programa de integração bilateral entre Brasil e Argentina, com o fim dos regimes militares em ambos os países. Destacam-se o Programa de Integração ArgentinaBrasil (PICAB), e o Tratado de Integração, Cooperação e Desenvolvimento, ambos assinados em Buenos Aires, respectivamente, em 1985 e 1988.

\footnotetext{
9 Assinado em Marrakech, em 12 de abril de 1994, entrou em vigor em $1^{\circ}$ de janeiro de 1995. 10 "As empresas tendem a maximizar seus benefícios, razão pela qual se estabelecerão onde lhes custe mais barato desenvolver-se. Consequentemente, a livre circulação provocará fortes oscilações no mercado em atenção às distintas regulações. As empresas produzirão onde a mãode-obra ou a energia elétrica sejam mais baratas e venderão onde os controles sejam menores"; LORENZETTI, Op. cit., p. 67-68.

11 A Comissão Econômica para América Latina (CEPAL), criada em 1948, consiste na principal fonte mundial de informação e análise sobre a realidade econômica e social latino-americana e, mais que isso, foi o único centro intelectual em toda região capaz de gerar um enfoque analítico próprio, que manteve vigente durante meio século. BIELSCHOWSKY Ricardo (2007) "Cinquenta anos de pensamento na Cepal". In RISTER Carla Abrantkoski (edit.) Direito ao Desenvolvimento: Antecedentes, Significados e Consequências. Rio de Janeiro: Renovar, p. 200.
} 
A Carta Constitucional do Brasil, de 1988, no seu art. $4^{\circ}$, descreve os princípios que regem as relações internacionais, estabelecendo a "cooperação entre os povos para o progresso da humanidade" como um princípio fundamental. Sendo que o país conta com a autorização constitucional para buscar a sua integração em uma comunidade latino-americana de nações, no parágrafo único do citado: "A República Federativa do Brasil buscará a integração econômica, politica, social e cultural dos povos da América Latina, visando à formação de uma comunidade latino-americana de nações".

A garantia do desenvolvimento nacional exposta na Constituição do Brasil, no art. $3^{\circ}$, II, e a cooperação entre os povos para o progresso da humanidade, disposta no art. $4^{\circ}$, flexibilizam o conceito de poder absoluto e perpétuo de soberania.

Em 26 de março de 1991, a República Argentina, a República Federativa do Brasil, a República do Paraguai e a Republica Oriental do Uruguai, assinaram o Tratado de Assunção ${ }^{12}$ para formação do Mercado Comum do Sul - MERCOSUL, objetivando "a ampliação das atuais dimensões dos seus mercados nacionais, através da integração constitui condição fundamental para acelerar seus processos de desenvolvimento econômico com justiça social".

Hodiernamente, integram o MERCOSUL, além dos países já citados, a República Bolivariana da Venezuela, Protocolo de Adesão de 2006, em fase final de adesão e o Estado Plurinacional da Bolívia, Protocolo de Adesão dezembro de 2012, em fase inicial de adesão. São países associados do MERCOSUL o Chile, a Colômbia, o Peru, o Equador, a Guiana e o Suriname ${ }^{13}$.

Destacam-se como textos normativos da estruturação do MERCOSUL, o Protocolo de Ouro Preto, assinado em 1994, define a estrutura institucional do MERCOSUL; o Protocolo de Olivos, de 2002, dispõe sobre a solução de controvérsias no MERCOSUL, mantendo as mesmas etapas para a solução das controvérsias previstas pelo Protocolo de Brasília, mas inclui o Tribunal Permanente de Revisão e o Protocolo Constitutivo do Parlamento do MERCOSUL, assinado em 2005.

O Protocolo de Olivos dispõe que: "As partes na controvérsia poderão acordar expressamente submeter-se diretamente e em única instância ao Tribunal Permanente de Revisão, caso em que este terá as mesmas competências que um Tribunal Arbitral "Ad Hoc" (art. 23)".

12 Tratado de Assunção (1991) - A República Argentina, a República Federativa do Brasil, a República do Paraguai e a República Oriental do Uruguai, doravante denominados "Estados Partes": (...) Convencidos da necessidade de promover o desenvolvimento cientifico e tecnológico dos Estados-Partes e de modernizar suas economias para ampliar a oferta e a qualidade dos bens de serviços disponíveis, a fim de melhorar as condições de vida de seus habitantes; Reafirmando sua vontade política de deixar estabelecidas as bases para uma união cada vez mais estreita entre seus povos, com a finalidade de alcançar os objetivos supranacionais".

13 SECRETARIA DO MERCOSUL (2013) “Quem Somos” [online] disponível em: http://www. mercosur.int $/$ t_generic.jsp? contentid $=4002 \&$ site $=1 \&$ channel $=$ secretaria\&seccion $=3$ [accesso em 28-10-2013]. 
Ademais, o regulamento do Protocolo de Olivos esclarece que o Conselho do Mercado Comum tem competência para estabelecer mecanismos relativos à solicitação de opiniões consultivas ao Tribunal Permanente de Revisão pelos Estados partes ${ }^{14}$.

A estrutura jurídica estabelecida para o MERCOSUL exige que os Estados Partes deixem de agir dentro dos seus ordenamentos jurídicos com "poder soberano exclusivo", para operarem em ordens jurídicas parciais à luz de "leis fundamentais regionais"

Nas legislações internas de cada país, torna-se relevante à definição de normas fundamentais delimitadoras, para dirimirem os conflitos relacionados ao desenvolvimento na competição entre os Estados Partes ${ }^{16}$.

No âmbito do Direito Empresarial, especificamente, no direito concursal, cabem às legislações dos Estados Partes do MERCOSUL, diante de possíveis crises insuperáveis: econômica, financeira ou patrimonial da atividade empresária, dispor sobre o melhor momento de liquidação do ativo para evitar ou minimizar os prejuízos dos credores ${ }^{17}$.

\section{AS NORMAS DE DIREITO CONCURSAL NOS MERCADOS INTEGRADOS DO MERCOSUL}

Os Estados Partes do MERCOSUL dispõem nas suas legislações internas sobre a recuperação de empresas e a falência.

Através de códigos ou leis esparsas o direito concursal nos Estados

14 Esclarece Alberto do Amaral Júnior: "O Protocolo de Olivos inovou ao permitir que os órgãos de cúpula do Poder Judiciário dos países membros formulem o pedido de opiniões consultivas. Se um juiz de instância inferior, ao analisar um caso concreto, vier a defrontar-se com a necessidade de aplicar o direito do MERCOSUL, poderá pleitear ao Tribunal Superior do Estado a que pertence, o encaminhamento de solicitação para que o TPR dissipe a dúvida porventura existente. (...) Diversamente do que acontece na Europa, as opiniões consultivas não dispõem de efeito vinculante no âmbito do MERCOSUL. Este é um obstáculo ponderável, que certamente afetará a adoção das opiniões consultivas no interior de cada país"; AMARAL JÚNIOR Alberto do (2013) "Reflexões sobre a solução de controvérsias do MERCOSUL". In Revista de la Secretaría del Tribunal Permanente de Revisión, 1(1), p. 13-28.

15 A "internacionalização" e a "europalização", no caso português, e a internacionalização e a "mercosulização", no contexto do Brasil, tornam evidente a transformação das ordens jurídicas nacionais em ordens jurídicas parciais, nas quais as constituições são relegadas para um plano mais modesto de "leis fundamentais regionais"; CANOTILHO J. J. Gomes (2012) "Brancosos" e interconstitucionalidade: itinerários dos discursos sobre a historicidade constitucional. $2^{\text {a }}$ ed. Coimbra: Almedina, p. 110.

16 "Este fenômeno produzirá um impacto relevante nas legislações nacionais, principalmente nos Códigos. Não se trata de que serão derrogados, mas, sim que são ignorados em virtude da vigência de leis especiais que se adaptem ao intercâmbio flexível. Haverá uma tendência muito mais séria à diminuição do protecionismo legal. Os países competirão entre si para ver quem oferece a legislação menos onerosa para a solução de problemas de desenvolvimento e desemprego. Dai resulta a importância da função delimitadora das normas fundamentais"; LORENZETTI, Op. cit., p. 67-68.

17 Neste contexto, Paulo Penalva Santos e Luís Felipe Salomão, aduzem que "esse é o grande desafio do direito falimentar moderno: equilíbrio entre o interesse social, a satisfação dos credores e o respeito aos direitos do devedor"; SANTOS Paulo Penalva, SALOMÃO Luís Felipe (2011) Recuperação Judicial, Extrajudicial e Falência. Rio de Janeiro: Forense, p.11. 
Partes do MERCOSUL está sujeito às transformações jurídicas que impõem a superioridade de sistema de normas fundamentais ${ }^{18}$.

$\mathrm{O}$ direito ao desenvolvimento é considerado um direito humano fundamental e deve exercer a força de gravidade de manter unidas as ordens jurídicas dos Estados Partes do MERCOSUL, na situação de crise da atividade empresária há necessidade da normatização mínima para se estabelecer uma base para a concorrência.

No Brasil, a Lei 11.101/2005 introduziu no ordenamento jurídico um novo tratamento para os empresários individuais e sociedades empresárias que estejam passando por crise econômico-financeira ou patrimonial, pois permite a recuperação da empresa como forma de solucionar as dificuldades da atividade empresarial não necessitando liquidar a atividade empresária, reconhecendo a importância da manutenção da empresa para o desenvolvimento econômico-social.

Dos institutos tratados na Lei 11.101/2005, tem-se a recuperação da empresa como gênero, sendo que o legislador optou em regulamentar para ordem jurídica brasileira as seguintes espécies: recuperação judicial e recuperação extrajudicial. Na primeira, o legislador deu tratamento diferenciado para o micro e pequeno empresário (Lei Complementar 123/2006).

No que tange a falência, a Lei 11.101/2005 introduziu mudanças visando extirpar a conotação da falência como meio coercitivo de recebimento de dívida e medidas para efetividade do princípio da preservação da empresa.

No ordenamento jurídico do Paraguai, a Lei 154/1969 disciplina a recuperação e a falência do comerciante e do não comerciante, que demonstrarem insolvência pelo descumprimento de uma ou mais obrigações ou por sinais externos de insuficiência patrimonial assim compreendido pelo Juiz.

Na Argentina, a Lei 24.522/1995 disciplina a falência e o acordo preventivo judicial e extrajudicial como espécies de recuperação para o empresário.

A Lei argentina foi alterada nos anos de 1997, 1999, 2002, 2006 e 2011 para introduzirem medidas para efetividade do princípio da preservação da empresa.

O Código de Comercial do Uruguai foi promulgado na segunda metade do século XIX, após as incorporações dos Decretos-leis 816, 817, 823 e terminada com a edição oficial do Decreto-lei no 841 de 24 de janeiro de 1866, dispondo sobre a promulgação e entrada em vigor a partir de $1^{\circ}$ de julho de 1866. No século XIX, o código ainda foi alterado pelo Decreto-lei no $917 / 1868$.

18 Ricardo Luís Lorenzetti salienta que "A ideia de superioridade no mundo atual é a de sistema de normas fundamentais, que se encontram nas "fontes superiores": Constituições, tratados, princípios, valores. (...) As normas fundamentais constituem uma espécie de força de gravidade que os mantém unidos". LORENZETTI, Op. cit., p. 79. 
O Código de Comercial Uruguaio ainda está em vigor, regula no Livro IV, arts. 1523 a 1781, os institutos da falência e da concordata preventiva. No Título XIX está regulada a Moratória, procedimento preventivo a declaração da falência.

A República Bolivariana da Venezuela disciplina a matéria comercial no Código de 1955, que derrogou o Código Comercial de 1904 e leis esparsas sobre as sociedades, tendo constituído um texto único.

O Código Comercial da Venezuela, Livro III (arts. 898 a 1081), dispõe sobre o atraso, a liquidação amigável e a falência.

No século XIX, influenciada pela França, a Bolívia aprovou seu primeiro Código Comercial (1834).

Em 1977, o Decreto Lei 14.379, de 25 de fevereiro, revogou o Código Comercial de 1834. No código de 1977, Livro IV, Título II, está regulado o concurso preventivo e as quebras, arts. 1487 a 1692.

Assim, descritas as leis esparsas e códigos comerciais dos Estados Partes do MERCOSUL, observa-se que apenas o Brasil promulgou uma nova lei sobre o direito concursal neste século. Na última década, a Argentina realizou alterações para adequar sua norma a nova visão do direito concursal. Os demais países mantiveram as leis e códigos dos séculos passados.

Nas normas dos Estados Partes do MERCOSUL há regulamentações de institutos de recuperação e da falência, sendo que apenas o Paraguai trata no mesmo texto legal a situação de crise do comerciante e não comerciante.

\subsection{A norma fundamental do direito concursal nos mercados integrados do MERCOSUL}

A falência é considerada o remédio legal quando se torna inviável manter a atividade, sendo que todas as legislações dos Estados Partes do MERCOSUL dispõem de espécies de recuperações, para tentar viabilizar a superação da crise antes de iniciar o processo liquidatório-solutório com a alienação do ativo para solver o passivo.

É salutar para o mercado de crédito que a atividade que não se sustenta seja retirada do mercado, com vistas a atender os interesses de todos que dele participam. Sendo fundamental à eficácia econômica do procedimento de liquidação que seja elevado ao máximo o montante de recursos e pagando do maior número de credores na falência ${ }^{19}$.

A análise do início do procedimento de liquidação dos bens nas

\footnotetext{
19 "A eficácia das normas e procedimentos se destina a reduzir (ou a não ampliar) perdas que seriam impostas à sociedade e, no caso da falência, diretamente aos credores". A impossibilidade de que todos recebam a totalidade de seus créditos porque o fato econômico é uma questão de sentido negativo em que o ativo é menor do que o passivo leva a pensar medidas como a distribuição das perdas segundo critérios de justiça e justiça social, evitar oportunismo e tomada de reféns, aumentar, tanto quanto possível tentar manter a atividade além de buscar obter o maior valor na liquidação dos ativos. SZTAJN Rachel (2006) Comentários à Lei de recuperação de empresas e falência. São Paulo: Saraiva, p. 372.
} 
legislações dos Estados Partes do MERCOSUL indica que Brasil ${ }^{20} \mathrm{e}$ Argentina ${ }^{21}$ adotam o termo $a$ quo para transformação dos ativos não líquidos em moeda, é o da juntada do auto de arrecadação dos ativos ao processo, com as descrições valorativas dos bens. Cabe ao auxiliar do Juízo alienar os bens dentro do plano aprovado para a venda e aos credores acompanharem o processo de falência em cartório.

No Brasil, em recente julgamento no Superior Tribunal de Justiça, o relator Ministro Paulo de Tarso Sanseverino, destacou como motivo para evitar a postergação do pagamento aos credores "que os juros vencidos após a decretação da falência, em regra, não são exigíveis, pois o artigo 124 da Lei 11.101 somente permite o seu pagamento após o adimplemento dos créditos subordinados, o que raramente acontece na prática. Nesse sentido, se a massa não paga juros, o custo pela indisponibilidade do capital cairá sobre o credor"22.

O Paraguai ${ }^{23} \mathrm{e}$ o Uruguai ${ }^{24}$ nas suas legislações dispõem sobre o início do procedimento de liquidação após o Síndico apresentar seu relatório com a avaliação dos bens e a formação da massa falida subjetiva (quadro geral de credores), sendo que a legislação do Uruguai faculta ao falido o pedido de concordata.

Já a Venezuela ${ }^{25}$ e a Bolívia ${ }^{26}$ dispõem do início do procedimento de

20 Lei 11.101/2005, Art. 139: Logo após a arrecadação dos bens, com a juntada do respectivo auto ao processo de falência, será iniciada a realização do ativo.

21 Lei 24.522/1995, Artículo 203: Oportunidad. La realización de los bienes se hace por el síndico y debe comenzar de inmediato salvo que se haya interpuesto recurso de reposición contra la sentencia de quiebra, haya sido admitida por el juez la conversión en los términos del artículo 90, o se haya resuelto la continuación de la explotación según lo normado por los artículos 189, 190 y 191. (Artículo sustituido por art. 26 de la Ley No 26.684 B.O. 30/06/2011).

22 Resp 1300455, MINISTRO PAULO DE TARSO SANSEVERINO, TERCEIRA TURMA, Data do Julgamento: 17/10/2013.

23 Lei 154/1969, Artículo 138: Firme el auto de quiebra y efectuada la verificación de crédito, el síndico realizará los bienes de la masa en el más breve plazo.

24 D 917/1868, Artículo 1761: Si a los diez días de cerrado el estado de verificación y graduación de créditos, conforme al artículo anterior, el fallido no hubiese presentado propuesta de concordato, se procederá por el Síndico con absoluta prescindencia del fallido, a la liquidación del activo, mediante la venta en remate público y al mejor postor, de todos los bienes, derechos y acciones de la masa.

25 CÓDIGO COMERCIAL DA VENEZUELA, Artículo 960: Reunidos los acreedores en la primera junta general de que habla el número $5^{\circ}$ del artículo 937 , hará el juez que cada uno exhiba los documentos justificativos de su crédito, respecto de los cuales podrán hacerse las observaciones generales que ocurran en cuanto a su legitimidad.

Hecha la presentación, podrá cualquiera de los acreedores proponer que la liquidación de la quiebra se haga por los acreedores; y si la proposición tuviere el voto favorable de un número de ellos que represente más de la mitad de la totalidad de los créditos que figuren en el balance, el tribunal sin perjuicio del procedimiento penal a que hubiere lugar, acordará la liquidación por los acreedores.

26 CÓDIGO COMERCIAL DA BOLÍVIA, Artículo 1612: (ENAJENACION DE LOS BIENES). Una vez vencido el plazo fijado en el artículo 1644, sin que el quebrado presente proposición de convenio resolutorio o cuando ésta no sea aceptada por los acreedores, ni sea legalmente admisible o no sea homologado el convenio por el juez, o bien no sea dispuesta la continuación de la empresa, deberá procederse de inmediato a la enajenación de los bienes de la masa, proponiendo al juez la forma y modos de enajenación, sin perjuicio de la aplicación de lo 
liquidação de bens nas suas legislações depois de findas as consultas aos credores.

Em todos os procedimentos descritos nas legislações dos Estados Partes do MERCOSUL, há a necessidade de uma ação coletiva voluntária, de colaboração entre si, dos personagens do processo de falência, como instrumento de coesão a melhorar o funcionamento da sociedade.

Não se pode desconsiderando o sentido econômico da falência, que se mede pela relação entre rendimento obtido e o esforço despendido para tanto e, ainda, os interesses estratégicos de cada credor submetido ao processo de liquidação, que adotando a Teoria dos Jogos ${ }^{27}$ podem definir quais os alcances de seus próprios ganhos e dos demais envolvidos.

Independentemente do modelo econômico adotado por cada um dos Estados Partes do MERCOSUL, o pagamento dos credores é um dos principais objetivos da falência. Assim, à medida que se posterga o pagamento aos credores, maior parcela do ativo é despendida com os gastos da própria massa, reduzindo-se a parcela destinada aos credores concursais e impedindo que o procedimento cumpra sua função de todos receberem alguma importância por conta do crédito.

Salienta-se que o Tratado de Assunção propõe a livre circulação interna de pessoas, bens e serviços; a proteção interna e a coordenação de políticas econômicas, o que implica na flexibilização das leis dos Estados Partes do MERCOSUL para que possam atuar num mundo de grandes espaços econômicos.

\section{CONCLUSÕES}

O século XX foi marcado por Guerras Mundiais e crises macroeconômicas, que corroboraram para evolução do Estado. As Cartas Constitucionais passaram a descrever as regras e princípios voltados para justiça social.

A Constituição do Brasil, de 1988, assumiu uma postura ostensivamente social, tendo incorporado na sua essência valores sociais próprios do Estado Social, obviamente impôs obediência de todos aos ditames da solidariedade, a fim de que realmente se possa edificar uma sociedade justa. A soberania já não tem mais um caráter absoluto em prol da cooperação própria dos processos de integração na busca de

dispuesto en el artículo 1607.

27 Salienta Eduardo Goulart Pimenta in "Autonomia como princípio jurídico estrutural”. Direito Civil - Da Autonomia Privada nas situações jurídicas patrimoniais e existenciais. Atualidades II: Belo Horizonte. Del Rey. 2007, p. 306: "Para que possamos compreender, à luz da Teoria dos Jogos, como se portam e também como devem atuar os agentes econômicos vinculados a uma empresa em crise econômico-financeira, precisamos estabelecer os elementos de nosso modelo econômico: qual é o "jogo", quem são os "jogadores", qual é o "ganho" esperado por eles, quais são as opções de "estratégias" disponíveis para cada um e, por fim, quais os efeitos que as diferentes estratégias de ação podem promover para o alcance de seus próprios ganhos e dos demais envolvidos". 
benefícios para todos.

O direito ao desenvolvimento passou a ser classificado como direito humano fundamental pela ONU, assim também disposto no Tratado de Assunção, que constituiu o MERCOSUL, exige que as ordens jurídicas dos países garantam mecanismos para sua efetividade.

O direito privado, na seara do direito empresarial, especificamente, no direito falimentar moderno, deve propulsionar as mudanças de eliminar as ideias liquidatárias, para uma visão de manutenção da atividade empresária.

Não há mais espaço para ideia do direito falimentar que vislumbra na política liquidaria a solução para resolver os problemas econômicos da empresa. É sabida, a importância da atividade empresária para economia de uma sociedade, sua liquidação provoca consequências sérias para o Estado por atingir empregos e a produção de riquezas.

A efetividade do direito ao desenvolvimento como direito humano fundamental, fundado tanto no aspecto individual como social, impõem às legislações dos Estados Partes do MERCOSUL uma harmonização da matéria sobre o termo a quo para iniciar o procedimento de venda dos bens no processo liquidatário, para que a falência não se transforme num fim em si mesmo, sem efetividade prática para os credores.

$\mathrm{O}$ procedimento de liquidação dos bens, conforme regulado nas legislações de Brasil e Argentina, demonstra que o termo a quo da juntada do auto de arrecadação dos ativos ao processo de falência é capaz de efetivar o equilíbrio entre o interesse social (mantendo a atividade empresária, quando realizada a venda em bloco dos bens); a satisfação dos credores (quanto mais eficiente e rápida for à liquidação, menores serão as perdas imputadas aos créditos) e o respeito aos direitos do devedor (reduz a parcela do ativo despendida com os gastos da própria massa).

A adoção pelos Estados Partes do MERCOSUL de diferentes termos para iniciar o procedimento de vendas dos bens no processo de falência, contribui para que não haja uma diminuição nas oscilações do mercado, uma vez que o tempo de liquidação de ativos no processão de falência é considerado pelos empresários para valorar o custo de investir num determinado país.

\section{REFERÊNCIAS BIBLIOGRÁFICAS}

AMARAL JÚNIOR Alberto do (2013) "Reflexões sobre a solução de controvérsias do MERCOSUL". In Revista de la Secretaría del Tribunal Permanente de Revisión, 1(1), p. 13-28.

BIELSCHOWSKY Ricardo (2007) "Cinquenta anos de pensamento na Cepal”. In RISTER Carla Abrantkoski (edit.) Direito ao Desenvolvimento: Antecedentes, Significados e Consequências. Rio de Janeiro: Renovar, p. 200. 
BRASIL. PRESIDÊNCIA DA REPÚBLICA. <www2.planalto.gov.br > [accesso em 28-10-2013].

BRASIL. SUPERIOR TRIBUNAL DE JUSTIÇA. <www.stj.jus.br> [accesso em 28-10-2013].

CANOTILHO J. J. Gomes (2012) "Brancosos" e interconstitucionalidade: itinerários dos discursos sobre a historicidade constitucional. 2da. ed. Coimbra: Almedina.

COOTER Robert, ULLEN Thomas (2010) Direito \& Economia. Trad. Luís Marcos Sander, Francisco Araújo a Costa. 5ed. Porto Alegre: Bookman.

FACHIN Melina Girardi, PAULINI Umberto (2008) "Problematizando a eficácia dos direitos fundamentais nas relações entre particulares: ainda e sempre sobre a constitucionalização do Direito Civil". In FACHIN Luiz Edson e TEPEDINO Gustavo (org.) Diálogos sobre direito civil. v.2. Rio de Janeiro: Renovar.

FERREIRA Mauro Santos (2013) "Desenvolver é preciso". Mercado Comum: Revista Nacional de Economia e Negócios, 21(240), p. 20.

HESSE Konrad (1998) Derecho Constitucional y Derecho Privado. Madrid: Civitas.

LORENZETTI Ricardo Luis (1998) Fundamentos do Direito Privado. São Paulo: Revistas dos Tribunais.

PERLINGIERI Pietro (1999) Perfis do Direito Civil: introdução ao direito civil constitucional. Trad. de Maria Cristina de Cicco. Rio de Janeiro: Renovar.

PIMENTA Salienta Eduardo Goulart (2007) "Autonomia como princípio jurídico estrutural". In FIÚZA César, SÁ Maria de Fátima Freire de, NAVES Bruno Torquato de Oliveira (coords.) Direito Civil Da Autonomia Privada nas situações jurídicas patrimoniais e existenciais. Atualidades II. Belo Horizonte: Del Rey.

RISTER Carla Abrantkoski (2007) Direito ao Desenvolvimento: Antecedentes, Significados e Consequências. Rio de Janeiro: Renovar. SANTOS Paulo Penalva, SALOMÃO Luís Felipe (2011) Recuperação Judicial, Extrajudicial e Falência. Rio de Janeiro: Forense, p.11.

SECRETARIA DO MERCOSUL (2013) “Quem Somos" [online] disponível em: http:/ www.mercosurint/t generic.jsp?contentid $=4002 \&$ site $=1 \& \mathrm{channel}=$ secretaria\&seccion=3 [accessoem 28-10-2013].

SZTAJN Rachel (2006) Comentários à Lei de recuperação de empresas e falência. São Paulo: Saraiva, p. 372. 